\section{Guidelines update}

\author{
Oktay Demirkiran \\ From Targeted Temperature Management (TTM 2014) \\ Berlin, Germany. 6-7 November 2014
}

In cardiac arrest patients the primary goal is to restart the heart, return the patient to life, and keep the brain intact. In 1960 a landmark article described the outcome in CPR [1]. In 1964 Peter Safar published the first integrated approach to cardiac arrest, and recommended therapeutic hypothermia $(\mathrm{TH})$ for support recovery [2]. These two studies merged in the first American Heart Association guidelines for the treatment of cardiac arrest patients [3]. The most recent update of the ERC and American Heart Association guidelines were published in November 2010. The use of $\mathrm{TH}$ in cardiac arrest patients developed after two cornerstone studies which showed good neurological outcome when the body temperature decreased to 32 to $34^{\circ} \mathrm{C}$ after out-of-hospital cardiac arrest $[4,5]$. Hypothermia can prevent or reduce cellular damage in the post-cardiac arrest period [6]. Current resuscitation guidelines recommend use of $\mathrm{TH}$ as soon as possible following return of spontaneous circulation [7]. Most TTM protocols call for induction with cold intravenous saline and surface cooling with cold packs while $\mathrm{TH}$ devices are being applied. Since then TTM of 32 to $34^{\circ} \mathrm{C}$ for 12 to 24 hours has been recommended as part of post-resuscitation care by international guidelines. Frydland and colleagues assessed mild hypothermia in 12 studies in patients with out-of-hospital cardiac arrest and nonshockable rhythms as an initial one [8]. TTM has been recommended for nonshockable rhythms [9]. Some observational studies supported the use of TTM in out-of-hospital cardiac arrest and initial nonshockable rhythms $[10,11]$.

The new resuscitation guidelines will represent the most recent and comprehensive analysis of intubation or supraglottic airway devices, mechanical devices, adrenaline use, telephone CPR, hypothermia/TTM, early PCI, and postarrest care. In the new guidelines in 2015 there may be answers for the optimal temperature target, duration of $\mathrm{TH}$, and rates of cooling and rewarming for post arrest.

\section{Financial disclosure}

OD has received speaker's reimbursement from C. R. BARD.

Published: 24 June 2015

\section{References}

1. Kouwenhoven WB, Jude JR, Knickerbocker CG: Closed chest cardiac massage. JAMA 1960, 173:1064-7.

2. Safar PJ: Community wide cardiopulmonary resuscitation. J lowa Med SoC 1964, 54:629-35.

3. Statement by the Ad Hoc Committee on Cardiopulmonary Resuscitation of the Division of Medical Sciences National Academy of Sciences-National Research Council: Cardiopulmonary resuscitation. JAMA 1966, 198:372-9.

4. The Hypothermia After Cardiac Arrest Study Group: Mild therapeutic hypothermia to improve the neurologic outcome after cardiac arrest. N Engl J Med 2002, 346:549-56.

5. Bernard SA, Gray TW, Busit MD, et al: Treatment of comatose survivors of out of hospital cardiac arrest with induced hypothermia. $N$ Engl J Med 2002, 346:557-63.

6. Polderman KM: Mechanisms of action, physiological effects, and complications of hypothermia. Crit Care Med 2009, 37(July 7 Suppl): S186-202.

7. Nolan JP, Morley PT, TL Hack Vanden, Hickeg RW: Therapeutic hypothermia after cardiac arrest: an advisory statement by the advanced life support task force of the international liaison committee on resuscitation. Circulation 2003, 108:118-21.

8. Frydland $M$, Kjaergaard J, Erlinge D, et al: Target temperature management of $33 \mathrm{C}$ and $36 \mathrm{C}$ in patients with out-of-hospital cardiac arrest with initial non-shockable rhythm - a TTM sub-study. Resuscitation 2015, 89:142-8.

9. Deakin CD, Nolan JP, Soar J, et al: European Resuscitation Council guidelines for resuscitation 2010 Section 4. Adult advanced life support. Resuscitation 2010, 81:1305-52.

10. Arrich J, European Resuscitation Council Hypothermia After Cardiac Arrest Registry Study Group: Clinical application of mild therapeutic hypothermia after cardiac arrest. Crit Care Med 2007, 35:1401-7.

11. Testori C, Sterz F, Behringer W, et al: Mild therapeutic hypothermia is associated with favourable outcome in patients after cardiac arrest with non-shockable rhythms. Resuscitation 2011, 82:1162-7.

doi:10.1186/1471-227X-15-S1-A15

Cite this article as: Demirkiran: Guidelines update. BMC Emergency

Medicine 2015 15(Suppl 1):A15. 